\title{
How to improve worldwide early enteral nutrition performance in intensive care units?
}

\author{
Arthur Raymond Hubert van Zanten(0) \\ See related research by Juan Xing et al., https://ccforum.biomedcentral.com/articles/10.1186/s13054-018-2159-x
}

Early enteral nutrition (EEN), typically started within $48 \mathrm{~h}$ after ICU admission, is recommended to be superior over delayed enteral nutrition and parenteral nutrition. The ESICM Working Group on Gastrointestinal Function provided clinical practice guidelines on EEN and suggested to initiate it at a low rate, as beneficial effects regarding infection prevention have been demonstrated in critically ill patients, as well as in patients with severe acute pancreatitis and after gastrointestinal (GI) surgery [1].

Delaying EN was only suggested in patients with uncontrolled shock (when hemodynamic and tissue perfusion goals are not met despite fluids and vasopressors), in uncontrolled hypoxemia and acidosis, uncontrolled GI bleeding, overt bowel ischemia (occlusive or non-occlusive), bowel obstruction (mechanical ileus), abdominal compartment syndrome, gastric aspirate volume (GRV) $>500 \mathrm{ml} /$ $6 \mathrm{~h}$ or high-output fistula if reliable distal feeding access is not achievable. These temporary contraindications are not present in the majority of ICU patients. The recommendations have been adopted in the new nutrition guidelines for adult ICU patients by the European Society for Clinical $\mathrm{Nu}-$ trition and Metabolism (ESPEN) as of September 2018, soon to be published in Clinical Nutrition (P. Singer, Madrid, personal communication ESPEN Congress].

\section{What is the actual worldwide early enteral feeding performance?}

In a cross-sectional, observational study in eight LatinAmerican countries among 1053 patients from 116 hospitals, caloric intake failed to meet the daily target in $40 \%$ of patients on day 1 [2]. Other observations were reported from the Nutrition Day ICU study concerning a 7-year worldwide prevalence study of nutrition

\section{Correspondence: zantena@zgv.nl}

Department of Intensive Care Medicine, Gelderse Vallei Hospital, Willy Brandtlaan 10, 6716, RP, Ede, The Netherlands practices in ICUs; more than $40 \%$ of the patients were not fed during the first day [3].

\section{What is the actual early enteral feeding performance in China?}

In a recent study published in Critical Care, an even more significant gap between the EEN recommendations and the actual feeding performance in Chinese ICUs was reported $[4,5]$. Only one-third of the patients received EN within two days. The proportion of subjects receiving $>80 \%$ of the energy target was only $4.8 \%$ after three days and $8.2 \%$ after one week. Significantly lower EN intakes among male patients were observed, possibly due to their higher body weight. However, when the median volume of EN administered of precisely $1000 \mathrm{ml}$ in all patients is combined with the findings of the gender effect, it seems that a standard dose of $1000 \mathrm{~mL}$ is provided to many patients, irrespective of their estimated caloric or protein needs. This median volume probably reflects a more or less one size fits all strategy. Similar observations were done in other countries [3]. These findings suggest that no personalized strategies are implemented and the guidelines are not followed.

\section{How to improve worldwide performance?}

In a review by Kozeniecki and coworkers [3], many barriers and solutions to delivery of ICU nutrition therapy are addressed. Based on national or local opinions, however, protocols and implementation strategies have to be adjusted to overcome the challenges and improve performance. Let's take China as an example.

\section{How to overcome the barriers in China?}

Based on a survey among 162 physicians from 45 ICUs in China we know that the attitude towards American guidelines is positive; $94 \%$ of the respondents consider nutrition therapy very important and $80 \%$ mention using

(c) The Author(s). 2018 Open Access This article is distributed under the terms of the Creative Commons Attribution 4.0 International License (http://creativecommons.org/licenses/by/4.0/), which permits unrestricted use, distribution, and 
the American guidelines [6]. However, more negative opinions were noticed for supplemental parenteral nutrition (59\%) and the cut-off values for GRV (41\%). These negative opinions may reflect the preference of Chinese physicians to start with early parenteral nutrition and later advance to EN.

When we consider the average weight of Americans and Europeans to be 81 and $71 \mathrm{~kg}$, respectively, and compare these with the weight of the Chinese patients $(65 \mathrm{~kg})$ in the Juan Xing study, this could imply that the cut-off for GRV in China should be $10-20 \%$ lower, thus $400-450 \mathrm{~mL} / 6 \mathrm{~h}[4,7]$. In this study, however, the median GRV was $0 \mathrm{~mL}$ (IQR $0-50 \mathrm{~mL}$ ) and therefore does not indicate a threshold problem.

The configuration of the EN devices and staffing is adequate in China's tertiary hospitals treating neurocritical care patients [8]. Of the ten guidelines for EN practices, setting the energy target, choosing the EN tube, and monitoring the patient showed poor compliance, 56.2\%, $30.0 \%$, and $38.9 \%$, respectively.

\section{Create change}

Based on the rules of change management the first step is to create the awareness that the performance is not in line with international recommendations. The results from the international and Chinese observational studies suggest that many ICU patients do not benefit from EEN. In Fig. 1 a simple strategy to improve EEN performance is suggested. A slightly lower GRV is suggested for the Chinese population; however, all the other improvement steps could be applied throughout the world.

\section{Is there evidence that enteral nutrition improvement strategies work in China?}

Nasogastric tube feeding of critically ill patients in a Chinese neurosurgical ICU was markedly improved after the implementation of a best practice strategy [9]. Collaboration, education, monitoring, and a reward system were the essential elements driving this success.

Also, EN protocols may help. The effectiveness of an EN protocol was studied in a before and after study among Chinese critically ill patients. The proportion of enteral feeding improved significantly after protocol implementation [10].

Furthermore, improved outcomes in China have been suggested with EEN. In a propensity-matched study, EEN therapy in patients with emergency intestinal surgery significantly reduced the total number of patients with complications, early ileus, time to first defecation,

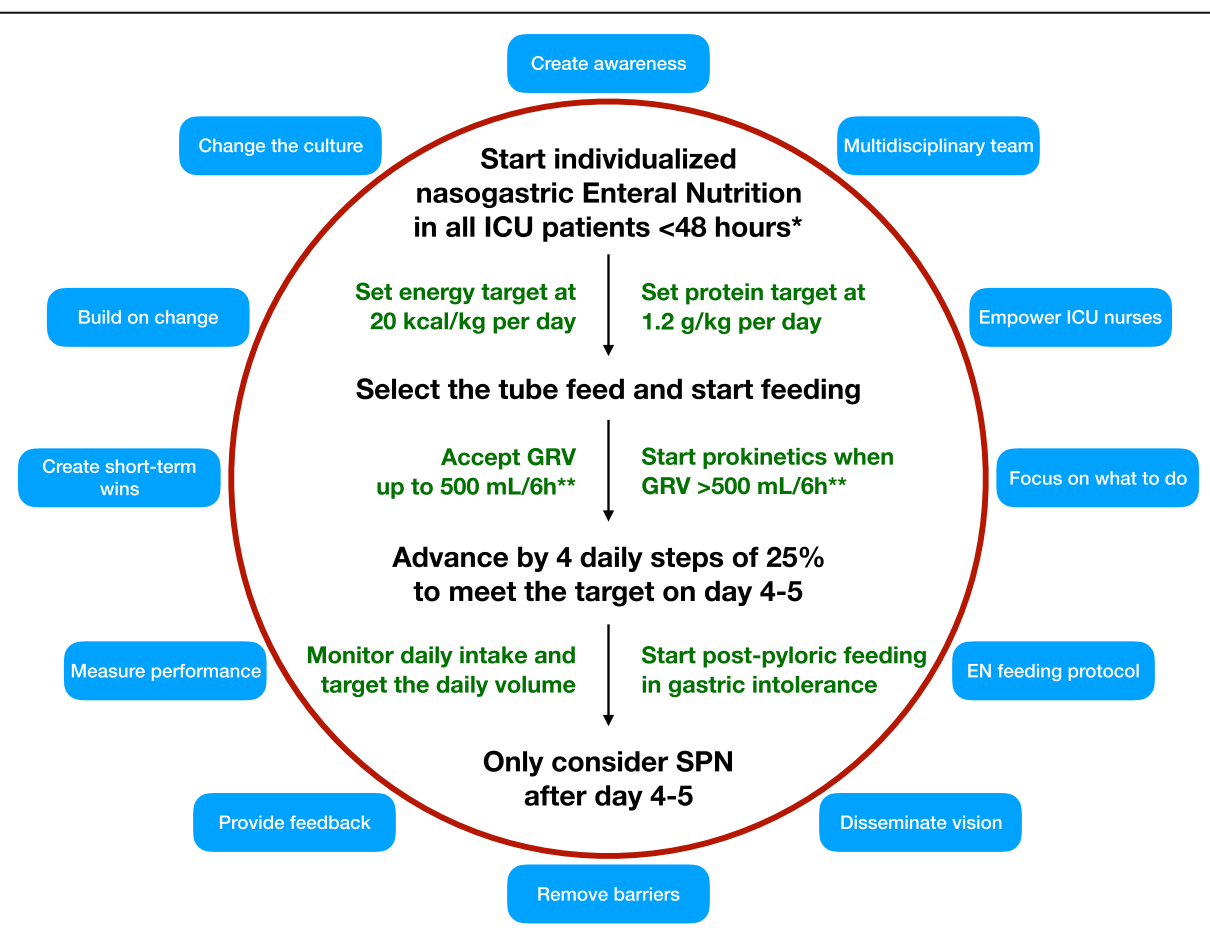

Fig. 1 Strategies to improve early enteral feeding performance. *When oral feeding is impossible or supposed not to achieve the targets. Delay enteral nutrition only in patients with uncontrolled shock (when hemodynamic and tissue perfusion goals are not met despite fluids and vasopressors), in uncontrolled hypoxemia and acidosis, uncontrolled Gl bleeding, overt bowel ischemia (occlusive or non-occlusive), bowel obstruction (mechanical ileus), abdominal compartment syndrome, gastric aspirate volume (GRV) $500 \mathrm{ml} / 6 \mathrm{~h}$ or high-output fistula if reliable distal feeding access is not achievable. ** Modified cut-off for GRV for the Chinese population: $400 \mathrm{ml} / 6 \mathrm{~h}$. Abbreviations: GRV gastric aspiration volume, EN enteral nutrition, Gl gastrointestinal, SPN supplemental parenteral nutrition 
length of hospital stay, mortality, and increased 28-day ICU-free days [11].

\section{Conclusion}

A multifaceted approach is warranted to improve the EEN performance in ICUs all over the world and in particular in China, involving all relevant stakeholders such as medical doctors, nutritionists and dieticians, nurses, healthcare assistants and, last but not least, patients and their families. This paper is an appeal to the international critical care, nutrition, and administrative leadership to initiate the change and improve enteral feeding practice in ICUs. Therefore, let's cooperate and follow the wisdom of the ancient Chinese proverb: "Talk does not cook rice".

\section{Acknowledgments \\ None.}

Funding

None.

Availability of data and materials

Not applicable.

\section{Author's contributions}

Dr. ARHvZ drafted and approved the final manuscript and is accountable for all aspects of the work.

Ethics approval and consent to participate

Not applicable.

\section{Consent for publication}

Not applicable.

\section{Competing interests}

Dr. van Zanten reported that he received honoraria for advisory board meetings, lectures, and travel expenses from Abbott, Baxter, BBraun, Cardinal Health, Danone-Nutricia, Fresenius Kabi, Lyric, and Nestlé-Novartis. Inclusion fees for patients in clinical trials were paid to the local ICU research foundation.

\section{Publisher's Note}

Springer Nature remains neutral with regard to jurisdictional claims in published maps and institutional affiliations.

Received: 9 August 2018 Accepted: 12 September 2018

Published online: 21 November 2018

\section{References}

1. Reintam Blaser A, Starkopf J, Alhazzani W, Berger MM, Casaer MP, Deane $A M$, et al. Early enteral nutrition in critically ill patients: ESICM clinical practice guidelines. Intensive Care Med. 2017;43(3):380-98.

2. Vallejo KP, Martínez CM, Matos Adames AA, Fuchs-Tarlovsky V, Nogales GCC, Paz RER, et al. Current clinical nutrition practices in critically ill patients in Latin America: a multinational observational study. Crit Care. 2017;21:227.

3. Kozeniecki M, Pitts $H$, Patel JJ. Barriers and solutions to delivery of intensive care unit nutrition therapy. Nutr Clin Pract. 2018;33(1):8-15. https://doi.org/ 10.1002/ncp.10051 Epub 2018 Jan 11.

4. Xing J, Zhang Z, Ke L, Zhou J, Qin B, Liang H, et al. Enteral nutrition feeding in Chinese intensive care units: a cross-sectional study involving 116 hospitals. Crit Care. 2018;22(1):229. https://doi.org/10.1186/s13054018-2159-x.
5. McClave S, Taylor B, Martindale R, Warren MM, Johnson DR, Braunschweig C, et al. Guidelines for the provision and assessment of nutrition support therapy in the adult critically ill patient: Society of Critical Care Medicine (SCCM) and American Society for Parenteral and Enteral Nutrition (A.S.P.E.N.). JPEN J Parenter Enteral Nutr. 2016;40:159-211.

6. Xu XL, Zhou JC, Pan KH, Zhao HC, Ying KJ. Attitudes toward the American nutrition guidelines for the critically ill patients of Chinese intensive care physicians. Asia Pac J Clin Nutr. 2015;24(2):347-58.

7. Walpole SC, Prieto-Merino D, Edwards P, Cleland J, Stevens G, Roberts I. The weight of nations: an estimation of adult human biomass. BMC Public Health. 2012;18(12):439.

8. Su YY, Gao DQ, Zeng XY, Sha RJ, Niu XY, Wang CQ, et al. A survey of the enteral nutrition practices in patients with neurological disorders in the tertiary hospitals of China. Asia Pac J Clin Nutr. 2016;25(3):521-8.

9. Xu Y, Ren $X$, Shi W, Jiang H. Implementation of the best practice in nasogastric tube feeding of critically ill patients in a neurosurgical intensive care unit. Int J Evid Based Healthc. 2013;11(2):128-33. https://doi.org/10. 1111/1744-1609.12020

10. Li Q, Zhang Z, Xie B, Ji X, Lu J, Jiang R, et al. Effectiveness of enteral feeding protocol on clinical outcomes in critically ill patients: A before and after study. PLoS One. 2017;12(8):e0182393.

11. Wang $H$, Zhao J, Wang $Y$, Tian $Y$, Xing $H$, Tai $H$, et al. Early enteral nutrition reduced postoperative ileus and improved the outcomes in patients with emergency intestinal surgery: results from a propensity score analysis. Int J Clin Exp Med. 2017;10(4):7040-8. 